\title{
Phenylthiocarbamide perception in epileptic patients on carbamazepine therapy
}

Imad A-J Thanoon*, Sabah K AL-Dabbagh**, Isam H.Mahmood*, Hilmy AS Abdul-Jabbar***

*Department of Pharmacology, Mosul College of Medicine, **Deparmtent of Clinical Pharmacy, College of Pharmacy, University of Mosul, ***Department of Neurosurgery, Ibn-Sena Hospital, Mosul, Iraq

TV.IT. T. I.

Received Accepted

1.7.T.1.

\begin{abstract}
The present study was designed to study the taste sensitivity to phenylthiocarbamide among epileptic patients. A total of $V r$ epileptic patients participated in the study. The epileptic state of the patients was well controlled by carbamazepine therapy, with their serum level of carbamazepine within therapeutic range. The other group consists of $7 r$ healthy volunteers, serving as a control. Test strips impregnated with phenylthiocarbamide have been used to identify tasters from non tasters of both patients and control groups. The individuals who perceive phenylthiocarbamide as bitter tasting was regarded as tasters while those describe it as tasteless were regarded as non-tasters. The results showed no significant difference with regard perception of phenylthiocarbamide between epileptic patients on carbamazepine therapy and controls.
\end{abstract}

Key words: phenylthiocarbamide taste sensitivity, epileptic patients, carbamazepine

الخلاصة

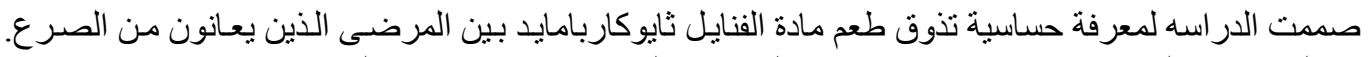

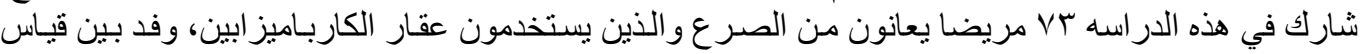

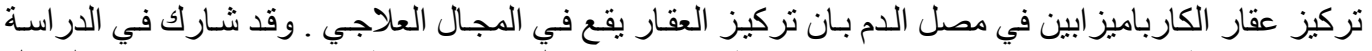

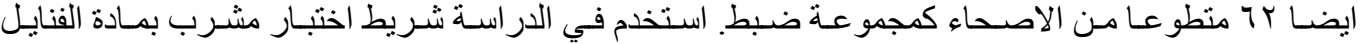

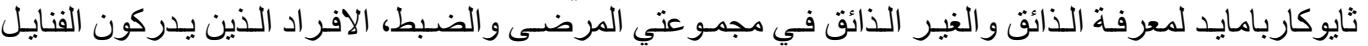

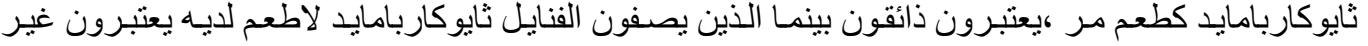

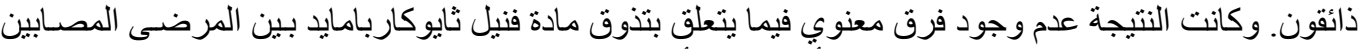
بالصر ع وتحت علاج عقار كاربامازبين و الأشخاص عدوف الأصحاء

$\mathrm{T}$ he ability or inability to taste the compound phenylthiocarbamide (PTC) is a classic inherited trait in humans and has been the subject of genetic and anthropological studies for over $v \cdot$ years.

This trait has also been shown to correlate with a number of a dietary preferences and thus may have important implications for human health '.
Fox set about testing a large number of people and found that distinct variation was common regardless of age, sex, and ethnicity ${ }^{r}$. Most interestingly Fox found that most people fall into just $r$ categories: those able to taste PTC even at a very low concentrations, whom he referred to tasters and those unable to taste the compound except at very high 
concentrations whom he referred to as non-tasters or taste blind ${ }^{r}$. 
Bitter taste perception is classically variable ${ }^{r}$. The prevalence of taste blindness (a lack of sensitivity to or an inability to taste bitter chemicals) ranges from $r \%$ in West Africa to $r_{-}$ $r$ r\% in China and $\Sigma . \%$ in India; $r . \%$ of the white North America populations have taste blindness ${ }^{r, \xi}$.

Studies of sensitivity of bitter tasting Phenylthiocarbamide have shown this to be an inherited trait determined by a dominant allele ${ }^{\circ}$. Investigators recently reported that haplotypic variation in the region of chromosome $(\mathrm{V})$ containing the TAS $r$ R $\wedge$ taste receptor gene shows a strong association with a bitter compound tasting ability. As such variation across TAS $r \mathrm{R} r \wedge$ is currently recognized as highly indicative of individual bitter compound-tasting ability ".

Some scientists are now interested in potential health application of genetic taste studies. For example, people who find PTC bitter are suspected to find the taste of cigarette bitter, which could make strong tasters less likely to smoke ${ }^{v}$.

There are also possible correlations between the ability to taste PTC and preferences for certain foods, which could influence a person's diet ${ }^{\wedge}$.

The ability to taste PTC has been associated with a number of medical and neurological illness not typically related to taste, and as a limited data are available which test the correlation between PTC tasters and non-tasters with epilepsy, the present study was designed to study the taste sensitivity to PTC among epileptic patients.

\section{Patients and methods}

A total of $V r$ epileptic patients $(\leqslant \tau$ idiopathic and $r V$ secondary generalized) participated in the study. The epileptic state of the patients was controlled by the antiepileptic drug, carbamazepine (SDI, Samara, $r \cdots \mathrm{mg}$ tablet). Other group consists of $7 r$ healthy volunteers, serving as controls, was also studied.

The epileptic patients consist of 09 males and $1 \leqslant$ females with a mean \pm SD age of rr. $r r_{ \pm} q . r r$ years. The control group consists of or males and 9 females with a mean \pm SD of $r$ r..$r$ \pm 9.०. years. The patients were collected from Neurology Outpatients Department, Ebn-Sina Hospital, Mosul, Iraq .

Test strips impregnated with Phenylthiocarbamide (Carolina Biological supply company, Burlington, N.C) have been used to identify taster from non-tasters of both patients and control groups. The individuals who perceive PTC, as bitter tasting is regarded as tasters, while those who describe it as tasteless are regarded as non-tasters.

Carbamazepine was administered in doses range of $\uparrow \cdots-\Lambda . . \mathrm{mg}$ daily. Serum carbamazepine concentration was measured in the serum of blood samples taken from all patients by a method using gas liquid chromatographic method ${ }^{q}$.

\section{Results}

Table I shows number and percentage of tasters and non-tasters among epileptic patients on carbamazepine therapy and controls. No significant difference with regard perception of phenylthiocarbamide was noticed between epileptic patients on carbamazepine therapy and controls.

Measuring serum carbamazepine levels revealed a range of $\varepsilon .1$ to $11 . r$ $\mu \mathrm{g} / \mathrm{ml}($ mean \pm SD: $7 . \wedge \leqslant \pm 1.07 \mu \mathrm{g} / \mathrm{ml})$ 
Table '. Frequency of PTC tasters and non-tasters in epileptics and controls

\begin{tabular}{|c|c|c|c|c|}
\hline \multirow{2}{*}{ parameters } & \multicolumn{2}{|c|}{ Non-tasters } & \multicolumn{2}{|c|}{ Tasters } \\
\hline & $\mathrm{N}$ & $\%$ & $\mathrm{~N}$ & $\%$ \\
\hline Patients & OV & $\mathrm{vA}$ & 17 & Y \\
\hline Controls & $\leqslant r$ & TV.V & r. & r.r.r \\
\hline
\end{tabular}

Chi-square test: $\cdot{ }^{\cdot 97} ; \mathrm{P}=\cdot .10$

\section{Discussion}

In the present study we examined PTC sensitivity in $V r$ patients and $r r$ healthy controls to determine whether taster status could represent a simple vulnerability marker. The results of the study revealed a higher prevalence of non-tasters in epileptic patients relative to healthy controls.

Review of the literature showed the presence of only one literature which test the prevalence of PTC tasters and non-tasters among epileptic patients.

The study was reported by Pal et $\mathrm{al}^{\prime}$, who showed that the frequency of PTC non-tasters is higher in the epileptic patients as compared with the healthy controls. These results are in agreement with our results .

The frequency of PTC tasters and non-tasters have been tested in another neurologic diseases including parkinsonism and psychotic diseases including depression and in smokers. PTC sensitivity was examined in TV schizophrenic patients, $r$. healthy controls and $r$. first degree relatives. A higher prevalence of non-tasters was seen in patients and family members relative to healthy controls"'. To identify genetic differences based on whether a bitter taste is perceived among smokers, Snedecor et al. studied a group of smokers, a higher number of non-tasters was reported as compared to tasters among the smoker group. They suggested that among smokers ability to taste PTC may confer some protection among smokers, from development of nicotine dependence and positive reinforcement from smoking. In other study, a higher proportion of non-tasters were found in patient with parkinsonism relative to healthy comparison subjects ${ }^{\prime r}$.

The epileptic patients in our study are controlled cases, their epileptic state was controlled by prophylactic doses of the antiepileptic drug carbamazepine as evident by the reduction of the epileptic fit during treatment and by the measurement of serum carbamazepine concentration, which revealed a therapeutic level in the sera of all patients. Wilson and Wilkinson ${ }^{14}$ showed that, the control of epilepsy by antiepileptic drugs depends on the blood level of the drug. Control of epilepsy by antiepileptic drug is obtained at therapeutic concentration of the drugs which is called therapeutic range ${ }^{\prime}$, which is for carbamazepine is $\left.\left(\varepsilon_{-}\right) \mathrm{r}\right) \mu \mathrm{g} / \mathrm{ml}^{10}$.

The prevalence of high frequency of non-tasters among epileptic patients in the present study and as phenotypic variations in PTC sensitivity is genetic 
in origin ", this may represent a surrogate risk factor for the development of epilepsy disease, and also this variation in the tasters and non-tasters may also explain the control of epileptic fits by the antiepileptic drug and reducing the likely of epileptic resistance to it.

\section{References}

1. Kim UK, Drayna D. Genetic of individual differences in bitter taste perception: lessons from the PTC gene. Clin. Genet r..o; TV: rvo rA.

$r$. Wooding S. Phenylthiocarbamide: A $V 0$-year adventure in genetics and natural selection. Genet $r \cdot . r ; Y Y r: r \cdot 10_{-} \cdot r \cdot r$.

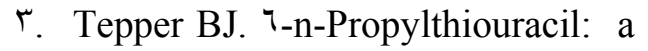
genetic marker for taste, with implications for food preference and dietary habits. Am J Hum

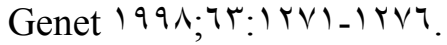

₹. Gou SW, Reed DR. The genetics of phenylthiocarbamide perception. Ann Hum Biol $r \ldots 1 ; r \wedge: 111$ _ $1 \leqslant$.

○. Reddy BM, Rao DC. Phenylthiocarbamide taste sensitivity revisited : complete sorting test supports residual family resemblance. Genet Epidemiol

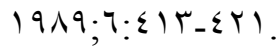

7. Kim UK, Jorgenson E, Coon H, Leppert M, Risch N , Drayna D. Positional cloning of the human quantitative trait locus underlying taste sensitivity to phenylthiocarbamide. Science r..r, r99:Irr) -Irro.

$\checkmark$. Snedecor SM, Pomerleau CS, Mehringer AM, et al. Differences in smoking- related variables based on phenylthiocarbamide "taster" status. Addict behave $r \cdots r ; r)$ : rT. Q_rTIr.
^. Phillips ML. Scientists find bitter taste gene. July $10, r \ldots r$. present at:K:/Neuroscience for kids-bitter Taste Gene.mht.

9. Hamid N. Evaluation of therapeutic drug monitoring in Ninevah province. M.Sc Thesis 199. College of Medicine-University of Mosul.

1.. Pal SK Sharma K, Pathak A, Sawhney IMS, et al. Possible relationship between phenylthiocarbamide taste sensitivity and epilepsy. Neurol India $r \cdot . \varepsilon ; 0 r: r \cdot r_{-} r \cdot q$.

1). Moberg PJ, Mc Gue C, Kanes SJ, Roalf DR, Balerston CC, Gur RE, Kohler CG, Turestsky BI. Phenylthiocarbamide (PTC) perception in patients with schizophrenia and first-degree family members: relationship to clinical symptomatology and psychophysical olfactory performance. Schizophr Res r..V;q.:YrIL $r$ rA.

Ir. Moberg PJ, Balderston CC, Rick $\mathrm{JH}$, et al. Phenylthiocarbamide (PTC) perception in Parkinson disease . Cogn Behav Neurol $\left.r \cdot v^{\prime} ; r_{0}: 1 \leq 0_{-}\right) \leq \Lambda$.

ir. Wilson JT, Wilkinson GR. Delivery of anticonvulsant drug therapy in epileptic patients assessed by plasma level analysis. neurol $19 \vee \leqslant ; r \leqslant: T 1 \leqslant-7 r r$.

I $\varepsilon$. Bertilsson L, Tomson T. Clinical pharmacokinetics and pharmacological effects of carbamazepine and carbamazepine$1 \cdot, 11$-epoxide. An update, Clin Pharmacokinet 1917;1): $1 V_{-} / 91$.

10. Dodson WE. Medical treatment and pharmacology of antiepileptic drugs. Pediatr Clin North Am 1919;rT:ET1_ETr 